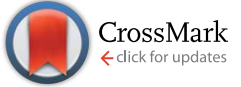

Cite this: RSC Adv., 2017, 7, 8090
Received 24th November 2016 Accepted 30th December 2016

DOI: 10.1039/c6ra27281a

www.rsc.org/advances

\section{Effective optimization of surface passivation on porous silicon carbide using atomic layer deposited $\mathrm{Al}_{2} \mathrm{O}_{3}$}

\author{
Weifang Lu, ${ }^{a}$ Yoshimi Iwasa, ${ }^{\mathrm{b}}$ Yiyu Ou, ${ }^{\text {a }}$ Daiki Jinno, ${ }^{\mathrm{b}}$ Satoshi Kamiyama, \\ Paul Michael Petersen ${ }^{a}$ and Haiyan Ou*a
}

Porous silicon carbide ( $\mathrm{B}-\mathrm{N}$ co-doped $\mathrm{SiC}$ ) produced by anodic oxidation showed strong photoluminescence ( $\mathrm{PL}$ ) at around $520 \mathrm{~nm}$ excited by a $375 \mathrm{~nm}$ laser. The porous SiC samples were passivated by atomic layer deposited (ALD) aluminum oxide $\left(\mathrm{Al}_{2} \mathrm{O}_{3}\right)$ films, resulting in a significant enhancement of the PL intensity (up to 689\%). The effect of thickness, annealing temperature, annealing duration and precursor purge time on the PL intensity of $A L D \mathrm{Al}_{2} \mathrm{O}_{3}$ films was investigated. In order to investigate the penetration depth and passivation effect in porous $\mathrm{SiC}$, the samples were characterized by $\mathrm{X}$-ray photoelectron spectroscopy (XPS) and time-resolved PL. The optimized passivation conditions (20 nm Al $\mathrm{O}_{3}$ deposited at $160{ }^{\circ} \mathrm{C}$ with purge time of $20 \mathrm{~s}$, followed by an annealing for 5 min at $350{ }^{\circ} \mathrm{C}$ ) for porous $\mathrm{SiC}$ were achieved and the results indicate that surface passivation by $\mathrm{ALD} \mathrm{Al}_{2} \mathrm{O}_{3}$ thin films is a very effective method to enhance the luminescence efficiency of porous SiC.

\section{Introduction}

Boron (B) and nitrogen (N) co-doped SiC can provide yelloworange light emission at room temperature. It has attracted significant attention as a candidate wavelength converter for SiC based white light-emitting diodes (LEDs). ${ }^{1,2}$ To realize a pure white LED with a high color rendering index, an emission component in the blue-green region is indispensable and porous $\mathrm{SiC}$ produced from bulk $\mathrm{B}-\mathrm{N}$ co-doped $\mathrm{SiC}$ is a potentially attractive material. By using quantum confinement effect of B-N donor-acceptor-pair (DAP) recombination and surface defects in porous $6 \mathrm{H}$-SiC, the emitting wavelength could be blue shifted to the blue-green spectra range..$^{3-5}$ The optical and electronic properties of porous SiC are mainly determined by the morphological properties of porous structures, which have been investigated intensively by using an anodic oxidation method. ${ }^{6,7}$ The morphology of porous SiC is usually determined by the experimental parameters such as the electrical current density, the composition of the etching solution and sample termination surface ( $\mathrm{Si}$ or $\mathrm{C}$ ) exposed to the etching solution. ${ }^{8}$

Although porous $\mathrm{SiC}$ is an attractive wavelength converter, the luminescence of porous SiC is not very stable because of the large sensitive surface area. Even exposure to ambient air can cause degradation of PL due to the surface oxidation. Therefore, investigation of the luminescence stabilization and

\footnotetext{
${ }^{a}$ Department of Photonics Engineering, Technical University of Denmark, DK-2800, Lyngby, Denmark. E-mail: haou@fotonik.dtu.dk

${ }^{b}$ Department of Materials Science and Engineering, Meijo University, 1-501 Shiogamaguchi, Tenpaku-ku, Nagoya 468-8502, Japan
}

enhancement is necessary, and surface passivation of dangling bonds is an effective way. To date, still very little work has been reported to improve the passivation effect in porous SiC. Normally, there are two passivation strategies for semiconductor interface or surface: reduction of the non-radiative defect states (dangling bonds) by atomic $\mathrm{H}$ or thin dielectric films; significant reduction of the electron or hole concentration by negativecharge-dielectric films (introduce electric field). ${ }^{9} \mathrm{Al}_{2} \mathrm{O}_{3}$ films are known to provide outstanding effect of passivation on the surfaces of semiconductor, which can provide both of passivation strategies. ${ }^{9-14}$ For porous $\mathrm{SiC}$, the important point to increase surface defects related photoluminescence is to reduce the non-radiative defect states (chemical passivation). Excess hydrogen introduced during the atomic layer deposition process is essential to the chemical passivation. The hydrogen atoms are usually bonded to the excess oxygen atoms and form -OH groups. ${ }^{12,15-18}$ It was observed that the passivation performance of $\mathrm{ALD} \mathrm{Al}_{2} \mathrm{O}_{3}$ can be activated by a post-annealing process. ${ }^{19}$ The surface passivation performance of $\mathrm{Al}_{2} \mathrm{O}_{3}$ films was found to depend on several conditions, i.e. the precursors, ${ }^{15,20}$ the deposition temperature ${ }^{21,22}$ and the post-deposition annealing temperature ${ }^{19,22,23}$ etc. The result in our previous work on porous $6 \mathrm{H}-\mathrm{SiC}$ without $\mathrm{B}$ doping has showed $250 \%$ enhancement of PL intensity. ${ }^{24}$ However, the passivation effect of ALD deposition processes, annealing conditions and the penetration depth on porous SiC haven't been investigated.

In this work, considering the importance of residual hydrogen content in the $\mathrm{Al}_{2} \mathrm{O}_{3}$ for passivating porous $\mathrm{SiC}$, we optimize the following parameters during the $\mathrm{ALD} \mathrm{Al}_{2} \mathrm{O}_{3}$ process: deposition temperature, $\mathrm{Al}_{2} \mathrm{O}_{3}$ thickness and purging 
time. The post-annealing temperature and duration are also investigated to avoid red shifting of the PL emission peak. The PL and XPS measurements were carried out to characterize the passivation effect in porous SiC. The optimization of passivation conditions on porous $\mathrm{SiC}$ is of great significance, as it provides a potential method to improve the luminescence efficiency in porous SiC.

\section{Experimental}

The porous $6 \mathrm{H}$-SiC samples were prepared from single crystalline $6 \mathrm{H}$-SiC wafer (TankeBlue, Beijing), doped with $\mathrm{N}(5.37 \times$ $\left.10^{18} \mathrm{~cm}^{-3}\right)$ and $\mathrm{B}\left(0.95 \times 10^{18} \mathrm{~cm}^{-3}\right)$. Both sides of the substrate have been polished and have a Si terminating face (Si-face). A layer of $100 \mathrm{~nm}$ nickel was evaporated on the back side of the SiC samples to form an ohmic contact, followed by a layer of $10 \mathrm{~nm}$ titanium and $200 \mathrm{~nm}$ layer of gold. After that, the samples were mounted into a Teflon cell with a platinum counter electrode (cathode), as shown in Fig. 1. The anodic oxidation was processed under a pulsed current of $3 \mathrm{~mA}$ with a period of $50 \mathrm{~ms}$ and duty ratio of $50 \%$. An aqueous solution with $5 \% \mathrm{HF}$ was used for electrolytes. The fabrication process was carried under UV light illumination (mercury-xenon lamp; $4.5 \mathrm{~W} \mathrm{~cm}^{-2}$ ) for 400 minutes. Under the pulsed current injection, $\mathrm{HF}$ electrolyte in the bath was circulated to reduce the adhesion of reactant $\mathrm{CO}_{2}$ bubbles. Finally, a porous layer with the thickness of $45 \mathrm{~nm}$ was obtained at the top surface. The color of the etched surface changed from transparent green to dark silver. For passivation optimization, porous samples a, $\mathrm{b}$ and $\mathrm{c}$ were fabricated under the same anodic etching conditions and further cleaved into small pieces $\left(a_{1}\right.$ to $a_{7}, b_{1}$ to $b_{10}$ and $\mathrm{c}_{1}$ to $\mathrm{c}_{4}$ ).

To investigate the passivation effect, the $\mathrm{Al}_{2} \mathrm{O}_{3}$ films were deposited on the porous samples in an ALD reactor (Model R200, Picosun, Finland), using trimethylaluminium (TMA: $\left.\mathrm{Al}\left(\mathrm{CH}_{3}\right)_{3}\right)$ and $\mathrm{H}_{2} \mathrm{O}$ gases as precursors for aluminum and oxygen, respectively. The precursors were alternately pumped into the reaction chamber in the ALD reactor by $\mathrm{N}_{2}$ carrier gas

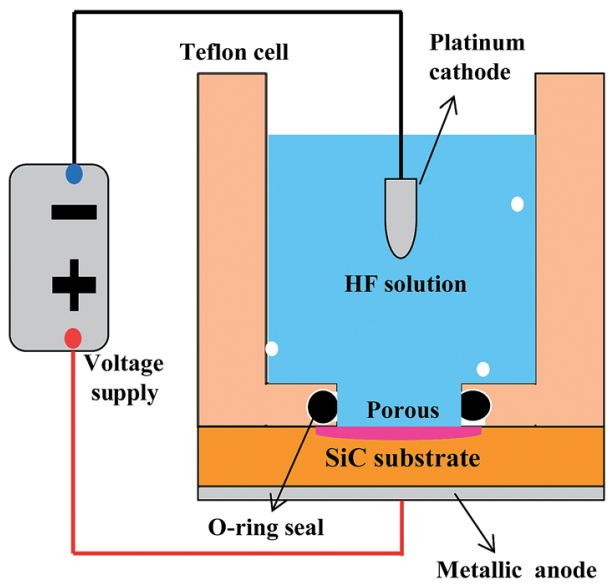

Fig. 1 Schematic diagram of the experimental set-up for anodic oxidation process. flow with the following sequence: $0.1 \mathrm{~s}$ TMA pulse, $3.0 \mathrm{~s} \mathrm{~N}_{2}$ purge, $0.1 \mathrm{~s}_{2} \mathrm{O}$ pulse, and $4.0 \mathrm{~s} \mathrm{~N}_{2}$ purge. One monolayer will be chemisorbed and retained on the surface of porous structures after one cycle. More details can be found in ref. 12 and 24 . To study the passivation performance, $8 \mathrm{~nm}, 20 \mathrm{~nm}$ and $50 \mathrm{~nm}$ thick $\mathrm{Al}_{2} \mathrm{O}_{3}$ were deposited at $160{ }^{\circ} \mathrm{C}$ for samples $\mathrm{a}_{2}, \mathrm{a}_{3}$ and $\mathrm{a}_{4}$ respectively. For comparison, samples $\mathrm{a}_{5}, \mathrm{a}_{6}$ and $\mathrm{a}_{7}$ were also covered with $8 \mathrm{~nm}, 20 \mathrm{~nm}$ and $50 \mathrm{~nm}$ thick $\mathrm{Al}_{2} \mathrm{O}_{3}$ deposited at $200{ }^{\circ} \mathrm{C}$. A post-deposition rapid thermal annealing (RTA) treatment of sample $\mathrm{a}_{2}, \mathrm{a}_{3}, \mathrm{a}_{4}, \mathrm{a}_{5}, \mathrm{a}_{6}$ and $\mathrm{a}_{7}$ were performed at $450^{\circ} \mathrm{C}$ for $30 \mathrm{~min}$ in $\mathrm{N}_{2}(10 \mathrm{sccm})$ environment.

The second batch of porous SiC samples (sample $b_{2}$ to $b_{10}$ ) covered with $20 \mathrm{~nm}$ thick of $\mathrm{Al}_{2} \mathrm{O}_{3}$ were used to optimize the annealing temperature and duration. Finally, $20 \mathrm{~nm}$ thick $\mathrm{Al}_{2} \mathrm{O}_{3}$ was deposited on the third batch of porous samples $c_{2}, c_{3}$ and $c_{4}$ with 3.0, 20.0 and $30.0 \mathrm{~s} \mathrm{~N}_{2}$ purge time, respectively.

The morphology of the porous SiC before and after passivation was inspected by scanning electron microscopy (SEM). The crystal structure in porous $\mathrm{SiC}$ was recorded by X-ray diffraction (XRD). The passivation effect can be observed visually from the enhancement of PL intensity. To investigate the annealing effect on passivation, XPS was used to distinguish the elemental composition. The penetration depth of $\mathrm{Al}_{2} \mathrm{O}_{3}$ films in the porous sample was analyzed by using a tunable beam of argon ions, then cycles of sputtering and measurement performed to measure the $\mathrm{Al}_{2} \mathrm{O}_{3}$ composition as a function of sample depth.

\section{Results and discussion}

\subsection{Morphology of the porous $\mathrm{SiC}$ covered with $\mathrm{Al}_{2} \mathrm{O}_{3}$}

The cross-sectional SEM images of porous $\mathrm{SiC}$ without and with $20 \mathrm{~nm}$ thick $\mathrm{Al}_{2} \mathrm{O}_{3}$ are shown in Fig. 2. The porous layer contains nano-triangular pores (marked by yellow triangle in Fig. 2(b)) with the size varying from $10-30 \mathrm{~nm}$. The pore morphology varied across the depth of the sample from the triangular to the dotted line. This is attributed to the non-uniformity of the localized electrode potential and electrolyte transportation in deep pore structures. However, the pores structures of porous $\mathrm{SiC}$ in this work are more uniform than that fabricated by direct current and without UV illumination. ${ }^{24}$ The triangular pores line up in an orderly arrangement and then pile up layer by layer. The distance between the two layers is constant. In addition, the neighboring layers are in some cases connected by nearly vertically oriented pores (labeled with an ellipse in Fig. 2(b)). It has been demonstrated that the formed anodized porous layer is single-crystal $6 \mathrm{H}-\mathrm{SiC} .{ }^{25}$ Thus, the triangular pore can be used to identify the crystallographic orientation of the preferential etch planes and their variations with depth. Fig. 2(b) also shows very small structures (microcrystallites) between two adjacent pores which conform to the condition of quantum confinement with dimensions of $2-5 \mathrm{~nm}$. However, for $6 \mathrm{H}-\mathrm{SiC}$ (energy bandgap of $3.1 \mathrm{eV}$ ), the luminescence peak of quantum structure should be located in UV range, which will not be investigated in this work. After depositing $20 \mathrm{~nm}$ thick $\mathrm{Al}_{2} \mathrm{O}_{3}$, the pores in the top layer are almost filled. The passivation boundary is not clearly observed in the SEM image, but it 


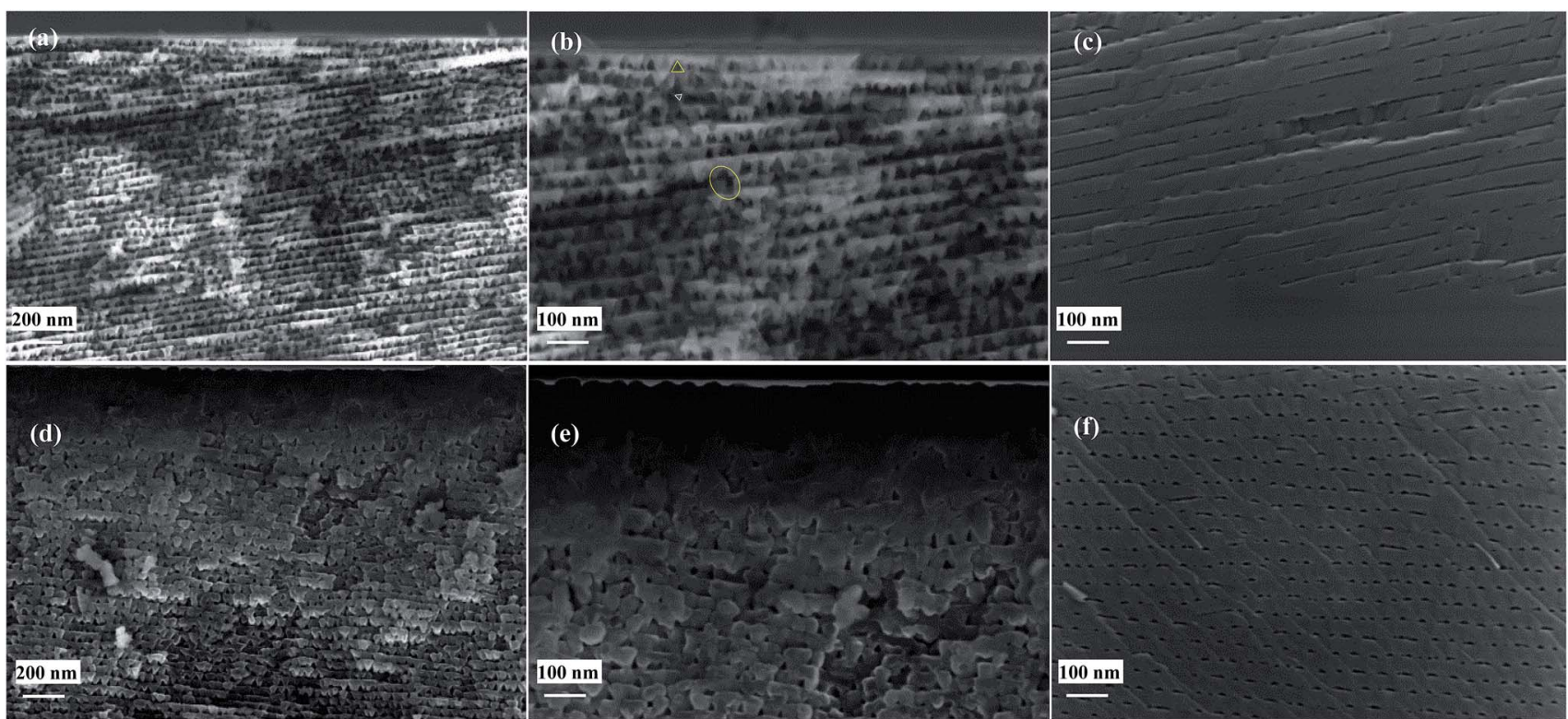

Fig. 2 Cross-sectional SEM images of porous $\mathrm{SiC}$ top layer (a) before and (d) after $\mathrm{Al}_{2} \mathrm{O}_{3}$ passivation ( $20 \mathrm{~nm}$ ). Enlarged view of the top layer before (b) and after passivation (e), and enlarged view of the bottom layer before (c) and after passivation (f).

appears that the bottom layer is not covered with $\mathrm{Al}_{2} \mathrm{O}_{3}$. The passivation depth will be further investigated by XPS measurement.

\subsection{X-ray diffraction characterization of porous $\mathrm{SiC}$}

The crystal properties of original flat and porous samples have been characterized by XRD patterns using a Rigaku SmartLab® XRD system, with $\mathrm{Cu} \mathrm{K} \alpha$ radiation from a $\mathrm{Cu}$ source $(\lambda=1.5406$ $\AA$ ). There are two obvious reflections from the crystal planes of 6H-SiC matrix, as shown in Fig. 3(a). The two main peaks are located at the angles of $35.60^{\circ}$ and $75.38^{\circ}$, which corresponding to the planes (006) and (0012) of $6 \mathrm{H}-\mathrm{SiC}$, respectively. Details of the intensive XRD peaks located at $35.60^{\circ}$ are presented in Fig. 3(b). It could be seen that two additional shoulder peaks $\left(35.40^{\circ}\right.$ and $\left.35.80^{\circ}\right)$ appeared in the porous samples. These peaks can be attributed to the reflection from surface inclusions on triangular pores, such as dangling bonds and $\mathrm{Si}$ related oxide. After passivated by $20 \mathrm{~nm} \mathrm{Al}_{2} \mathrm{O}_{3}$, the symmetric shoulder peaks became sharper due to the saturation of dangling bonds.

\section{3 $\quad \mathrm{Al}_{2} \mathrm{O}_{3}$ thickness optimization}

To optimize the thickness, a layer of $8 \mathrm{~nm}, 20 \mathrm{~nm}$ and $50 \mathrm{~nm}$ thick $\mathrm{Al}_{2} \mathrm{O}_{3}$ was deposited on porous sample $\mathrm{a}_{2}, \mathrm{a}_{3}$ and $\mathrm{a}_{4}$ at $160{ }^{\circ} \mathrm{C}$, respectively. In addition to this, porous samples $\mathrm{a}_{5}, \mathrm{a}_{6}$ and $\mathrm{a}_{7}$ were also covered with $8 \mathrm{~nm}, 20 \mathrm{~nm}$ and $50 \mathrm{~nm}$ thick $\mathrm{Al}_{2} \mathrm{O}_{3}$ deposited at $200{ }^{\circ} \mathrm{C}$, and followed by a $30 \mathrm{~min}$ annealing at $450{ }^{\circ} \mathrm{C}$. The passivation effect was characterized by $\mathrm{PL}$ measurements using a $375 \mathrm{~nm}$ laser as excitation source coupled into a microscope. After passivation, the PL intensity of porous samples $\mathrm{a}_{2}, \mathrm{a}_{3}$ and $\mathrm{a}_{4}$ increased by a factor of $105 \%$, $206 \%$ and $33 \%$ compared to reference sample $a_{1}$, respectively, as shown in Fig. 4(a). Fig. 4(b) shows that sample $\mathrm{a}_{6}$ also has the largest PL enhancement of $178 \%$ among sample $a_{5}, a_{6}$ and $a_{7}$.
However, the emitting peak of passivated porous samples is red shifted with $50 \mathrm{~nm}$ thick $\mathrm{Al}_{2} \mathrm{O}_{3}$. The cross-sectional SEM image in Fig. 2(d) shows that $20 \mathrm{~nm}$ of $\mathrm{Al}_{2} \mathrm{O}_{3}$ already fills the top layer of the porous sample. Excess oxygen atoms in $50 \mathrm{~nm}$ thick $\mathrm{Al}_{2} \mathrm{O}_{3}$
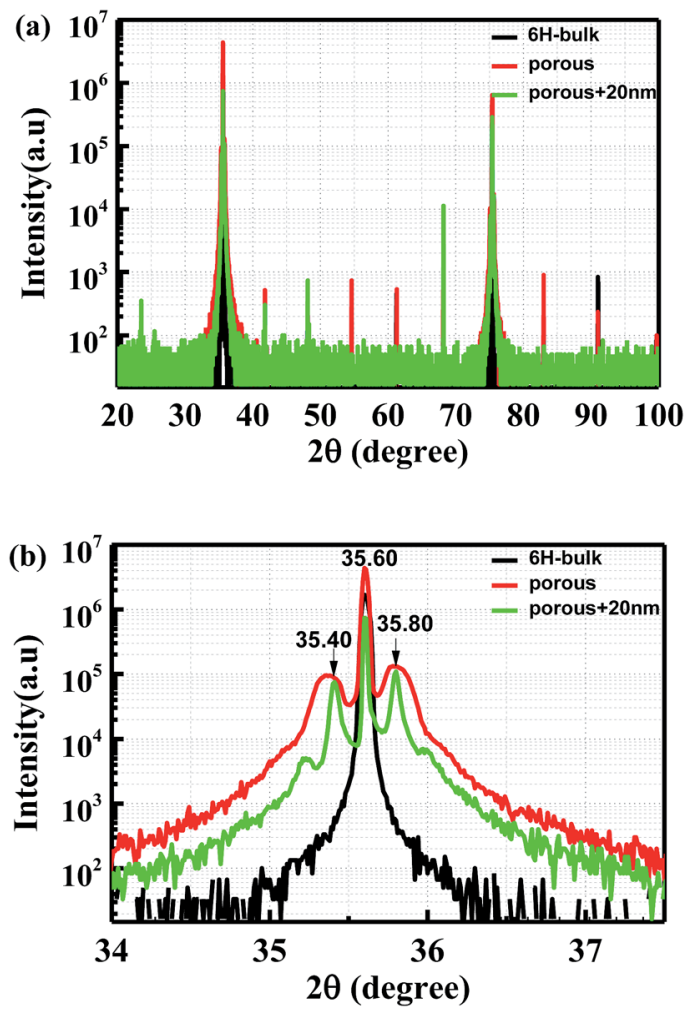

Fig. 3 (a) XRD diagram of bulk $6 \mathrm{H}-\mathrm{SiC}$, porous sample before and after passivation; (b) high intensity XRD peaks of the samples presented in more details. 

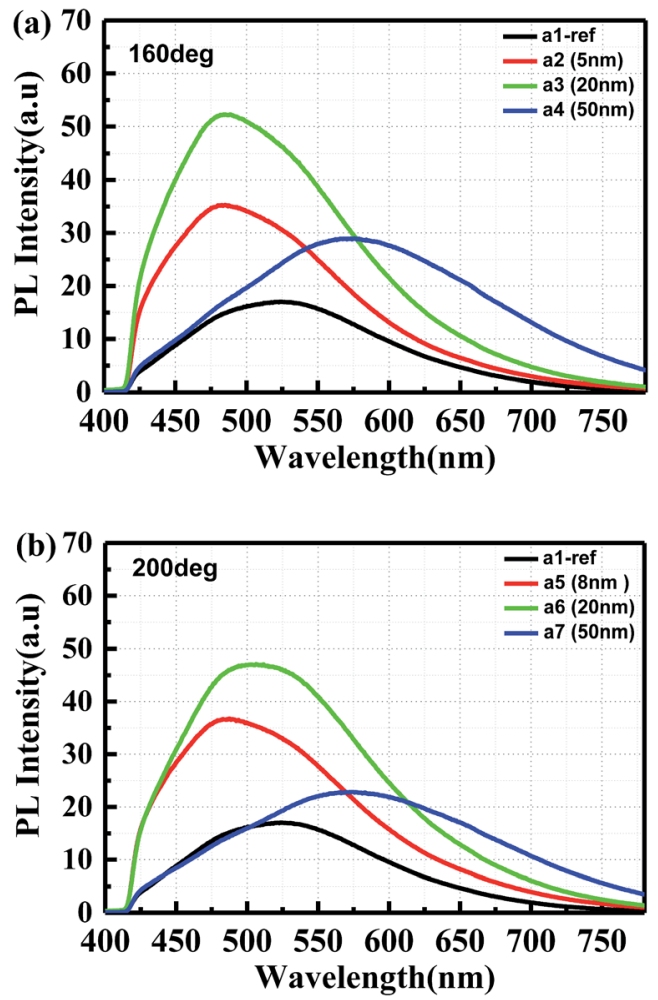

Fig. $4 \mathrm{PL}$ spectra of porous $\mathrm{SiC}$ covered by $5 \mathrm{~nm}, 20 \mathrm{~nm}$ and $50 \mathrm{~nm}$ $\mathrm{Al}_{2} \mathrm{O}_{3}$ film deposited at (a) $160{ }^{\circ} \mathrm{C}$ and (b) $200{ }^{\circ} \mathrm{C}$. The samples were annealed at $450{ }^{\circ} \mathrm{C}$ for $30 \mathrm{~min}$. Sample $\mathrm{a}_{1}$ is the original porous $\mathrm{SiC}$ for reference.

may oxidize the porous surface and increase the oxygen-related defects during the annealing process, leading to the red shift. ${ }^{24}$ Therefore, it reveals that the effective passivation thickness is $20 \mathrm{~nm}$ for the porous SiC samples.

\subsection{Impact of post-annealing conditions}

The surface passivation quality of $\mathrm{Al}_{2} \mathrm{O}_{3}$ films grown by ALD was investigated after annealing under various conditions, i.e. annealing with different time and temperatures ranging from $300{ }^{\circ} \mathrm{C}$ to $500{ }^{\circ} \mathrm{C}$. Based on the passivation results, all the samples were covered with $20 \mathrm{~nm} \mathrm{Al} \mathrm{O}_{3}$ films deposited at $160{ }^{\circ} \mathrm{C}$. Fig. 5 illustrates the passivation effect by PL measurement. Samples $b_{2}$, $b_{3}, b_{4}$ and $b_{5}$ were annealed for $5 \mathrm{~min}, 15 \mathrm{~min}, 30 \mathrm{~min}$ and $45 \mathrm{~min}$ at $450{ }^{\circ} \mathrm{C}$, which resulted in an enhancement by a factor of 5.70 , 5.57, 4.63 and 3.99, respectively, as shown in Fig. 5(a). Afterwards, the annealing temperature was also investigated for sample $b_{6}$, $\mathrm{b}_{7}, \mathrm{~b}_{8}, \mathrm{~b}_{9}$ and $\mathrm{b}_{10}$ with $5 \mathrm{~min}$ at $300{ }^{\circ} \mathrm{C}, 350{ }^{\circ} \mathrm{C}, 400{ }^{\circ} \mathrm{C}, 450{ }^{\circ} \mathrm{C}$ and $500{ }^{\circ} \mathrm{C}$, respectively. In Fig. 5(b), it can be seen that the enhancement for the passivated sample $b_{6}, b_{7}, b_{8}, b_{9}$ and $b_{10}$ is $2.79,5.40,5.89,5.70$ and 3.03 , respectively, compared to the reference sample $b_{1}$. However, the emission peak of sample $b_{8}, b_{9}$ and $b_{10}$ is slightly red shift due to the oxidation effect with higher annealing temperature. The surface passivation performance was found to depend on both the annealing temperature and the duration. For higher annealing temperatures and longer annealing times the passivation performances degrades. It also
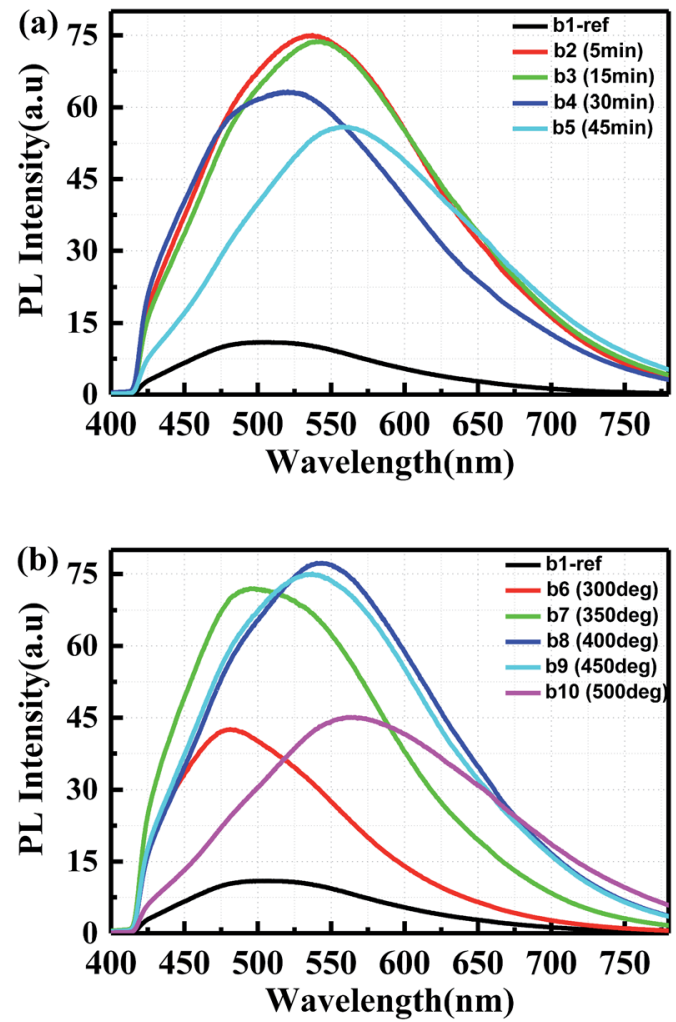

Fig. $5 \mathrm{PL}$ spectra in porous $\mathrm{SiC}$ samples covered by $20 \mathrm{~nm} \mathrm{Al}_{2} \mathrm{O}_{3}$ film deposited at $160{ }^{\circ} \mathrm{C}$ : (a) sample $b_{2}, b_{3}, b_{4}$ and $b_{5}$ were annealed for $5 \mathrm{~min}, 15 \mathrm{~min}, 30 \mathrm{~min}$ and $45 \mathrm{~min}$ at $450^{\circ} \mathrm{C}$, respectively; (b) sample $\mathrm{b}_{6}$, $b_{7}, b_{8}, b_{9}$ and $b_{10}$ were annealed at $300^{\circ} \mathrm{C}, 350^{\circ} \mathrm{C}, 400^{\circ} \mathrm{C}, 450^{\circ} \mathrm{C}$ and $500{ }^{\circ} \mathrm{C}$ for $5 \mathrm{~min}$, respectively.

can be deduced that the emission in porous $6 \mathrm{H}-\mathrm{SiC}$ is mainly attributed to the surface defects.

\subsection{Optimization of ALD purge time}

From the cross-sectional SEM images in Fig. 2, it can be seen that the pore size is around $15-30 \mathrm{~nm}$ and only the pores in the top layer are entirely filled by $\mathrm{Al}_{2} \mathrm{O}_{3}$. To verify the ALD penetration depth and how it affects the PL, different purge time in the ALD process was studied. Porous samples $c_{2}, c_{3}$ and $c_{4}$ were deposited with the purge time of $3.0 \mathrm{~s}, 20.0 \mathrm{~s}$ and $30.0 \mathrm{~s}$, respectively. The PL spectra are shown in Fig. 6(a) where the original porous sample $c_{1}$ ( $40 \mu \mathrm{m}$ thick of porous layer) is used for reference. After passivation, the PL enhancement for sample $\mathrm{c}_{2}, \mathrm{c}_{3}$ and $\mathrm{c}_{4}$ are 3.43, 5.50 and 2.75, respectively. Thus, $30.0 \mathrm{~s}$ purge time is too long for the passivation due presumably to oxidation in the ALD react chamber.

The cross-sectional PL distribution was also characterized to inspect the penetration depth, as shown in Fig. 6(b). The excitation laser is guided into a microscope with $20 \times$ objective. The acquisition spot size is $1.14 \mu \mathrm{m}$, while the collected illumination signal is integration from $520 \mathrm{~nm}$ to $600 \mathrm{~nm}$ within the same porous depth. Thus the results in the cross-sectional PL are not comparable with that in the normal PL spectra in Fig. 6(a). The distribution curve for reference sample $c_{1}$ shows that the emitted light intensity is uniform through the porous layer. It can be seen that the PL 

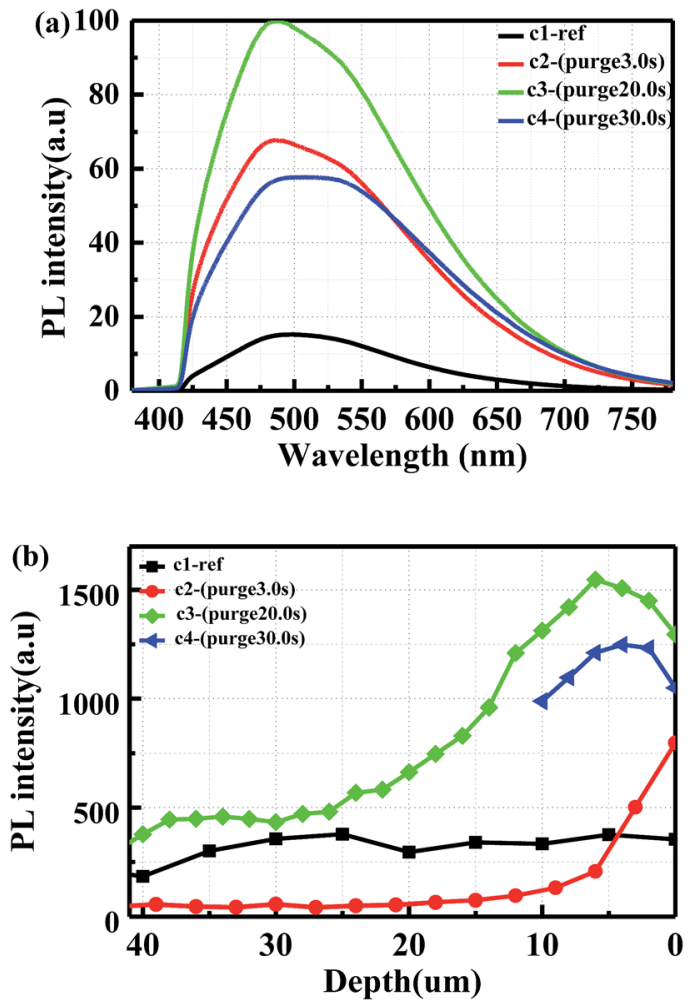

Fig. 6 (a) PL and (b) cross-sectional PL spectra in porous SiC covered by $20 \mathrm{~nm} \mathrm{Al} \mathrm{O}_{3}$ film deposited with different purge time. The purge time for $c_{2}, c_{3}$ and $c_{4}$ is $3.0 \mathrm{~s}, 20.0 \mathrm{~s}$ and $30.0 \mathrm{~s}$, respectively.

intensity in sample $c_{3}$ is higher than the other two samples within the top $6 \mu \mathrm{m}$ layer. However, the maximum point in sample $c_{3}$ and $\mathrm{c}_{4}$ is located about $6 \mu \mathrm{m}$ and $4 \mu \mathrm{m}$ beneath the surface respectively, which is attributed to the oxidation in the ALD chamber with much longer deposition time. Nevertheless, this trend is used to roughly judge the penetration depth of ALD deposition. A more accurate characterization for the optimized sample $c_{3}$ will be shown by XPS characterization in the following section.

\subsection{X-ray photoelectron spectroscopy characterization}

XPS measurements were performed to investigate the passivation mechanisms and $\mathrm{Al}_{2} \mathrm{O}_{3}$ penetration depth in porous SiC. Fig. 7 shows Al 2p core-level XPS spectra in as-deposited and annealed porous SiC samples with Gaussian fitting. The pass energy was set to $50.0 \mathrm{eV}$ for the measurements. The spectra were calibrated using $\mathrm{C} 1 \mathrm{~s}$ at $284.8 \mathrm{eV}$ as the internal reference to correct for charging. For as-deposited $\mathrm{Al}_{2} \mathrm{O}_{3}$ on porous $\mathrm{SiC}$, two components can be observed at the binding energies of $76.04 \mathrm{eV}$ and $76.9 \mathrm{eV}$, corresponding to $\mathrm{Al}-\mathrm{O}$ bonds and $\mathrm{Al}-\mathrm{OH}$ bonds, respectively. After annealing for $5 \mathrm{~min}$, the component at $76.9 \mathrm{eV}$ decreased, indicating the reduction of $\mathrm{Al}-\mathrm{OH}$ bonds during post-deposition annealing, as shown in Fig. 7(b). It should be noted here that the residual $\mathrm{Al}-\mathrm{OH}$ bonds existed during ALD deposition, which is easily broken and released within $\mathrm{Al}_{2} \mathrm{O}_{3}$ films. These released $\mathrm{H}$ atoms play an important role for the passivation performance in the porous layer. Such $\mathrm{H}$ atoms will diffuse and arrive at the $\mathrm{Al}_{2} \mathrm{O}_{3} / \mathrm{SiC}$ interface and thus neutralize the dangling bonds. ${ }^{17,23}$ This phenomenon is in consistent with that in XRD results.

In order to characterize the $\mathrm{Al}_{2} \mathrm{O}_{3}$ penetration depth, the porous sample $c_{3}$ was analyzed by XPS with argon ion sputtering time, using ion beam energy of $3 \mathrm{keV}$. The acquisition spot size for the measurement is $400 \mu \mathrm{m}$. The results are shown in Fig. 8 . Before sputtering, the intensity of $\mathrm{Al} 2 \mathrm{p}$ peak at $74.5 \mathrm{eV}$ was the mixed signal of $\mathrm{Al}_{2} \mathrm{O}_{3}$ and absorbed $\mathrm{CO}_{2}$ on the surface. The peak was slightly shifted to $75.2 \mathrm{eV}$ as the $\mathrm{CO}_{2}$ was sputtered off. However, the $\mathrm{Al}-\mathrm{O}$ peak in $\mathrm{Al} 2 \mathrm{p}$ remains at the same binding energy location without discernible change with increasing sputtering time. The Al-O peak in $\mathrm{O}$ 1s gradually shifts to a higher binding energy with increasing sputtering time, and the intensity also decreases due to the $\mathrm{Al}_{2} \mathrm{O}_{3}$ thickness decreasing in the deeper porous layer. Based on the sputtering rate, both $\mathrm{Al} 2 \mathrm{p}$ and $\mathrm{O} 1 \mathrm{~s}$ spectra could be used to qualitatively judge the passivation depth. The sputtering depth was measured to be $6.5 \mu \mathrm{m}$ using a profiler. When zooming in the signal in $\mathrm{Al} 2 \mathrm{p}$ with a sputtering time of $45 \mathrm{~min}$, the signal of Al-O bonds is still present. Thus the penetration depth for porous sample $c_{3}$ is at least $6.5 \mu \mathrm{m}$. Simultaneously, the $\mathrm{Si}-\mathrm{C}$ signal in $\mathrm{C} 1 \mathrm{~s}$ and $\mathrm{Si} 2 \mathrm{p}$ is increased with the sputtering time. In addition, it is accounted for the contamination caused by the air exposure, which leads to bonding of the surface carbon atoms with the oxygen or water molecules from the air.

\subsection{Time-resolved PL characterization}

To analyze the passivation effect, time-resolved PL measurements were used to characterize the porous samples. The measurements were performed at room temperature. For the
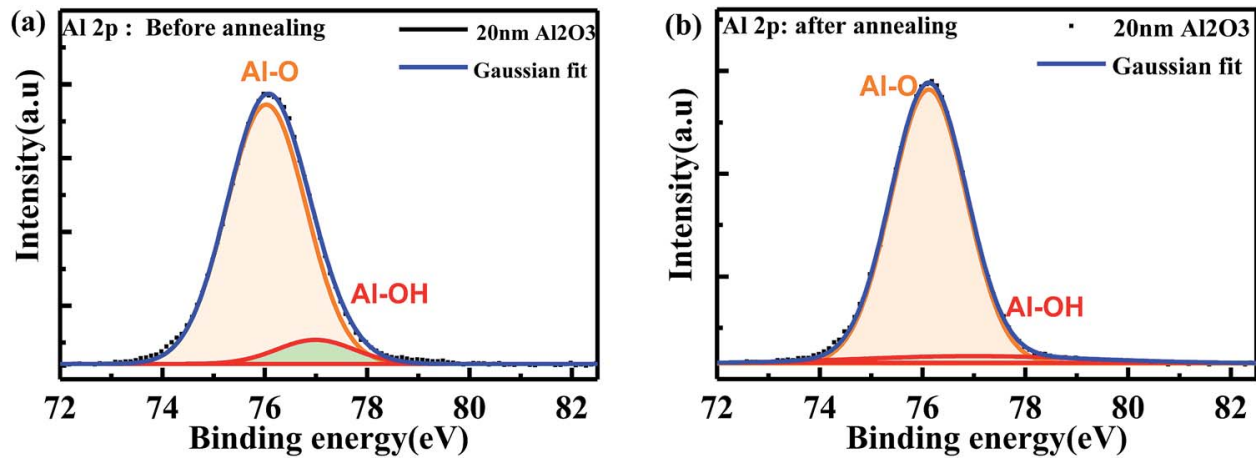

Fig. 7 XPS core level spectra of $\mathrm{Al} 2 \mathrm{p}$ in porous $\mathrm{SiC}$ covered by $20 \mathrm{~nm} \mathrm{Al} \mathrm{O}_{3}$ film: (a) as-deposited and (b) after annealing. 

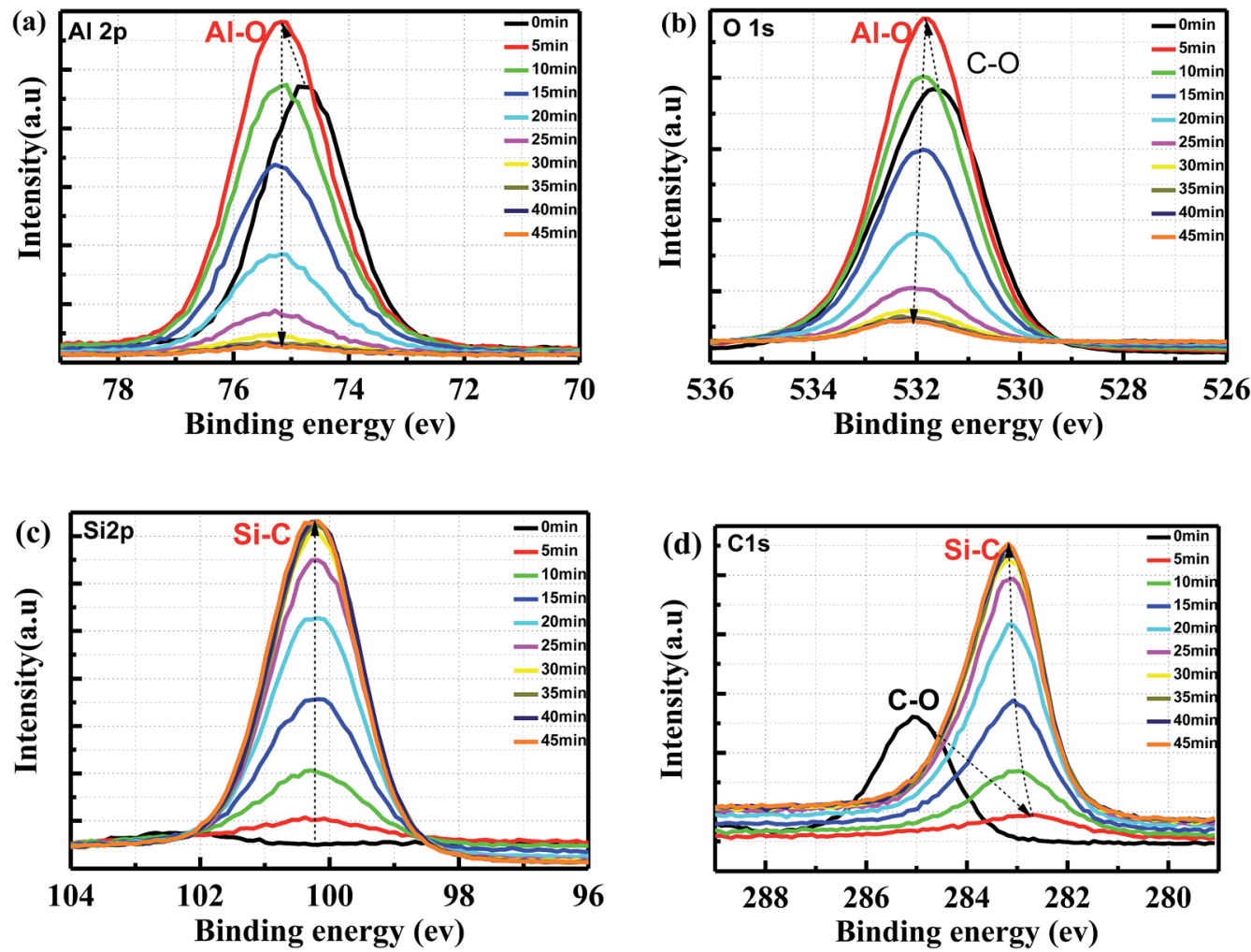

Fig. 8 XPS high resolution spectra of (a) Al 2p, (b) O 1s, (c) Si $2 p$ and (d) $\mathrm{C}$ 1s in porous SiC covered by $20 \mathrm{~nm} \mathrm{Al}_{2} \mathrm{O}_{3}$ : the sputtering ion-beam energy is $3 \mathrm{keV}$; acquisition spot size is $400 \mu \mathrm{m}$, with pass energy of $50 \mathrm{eV}$.

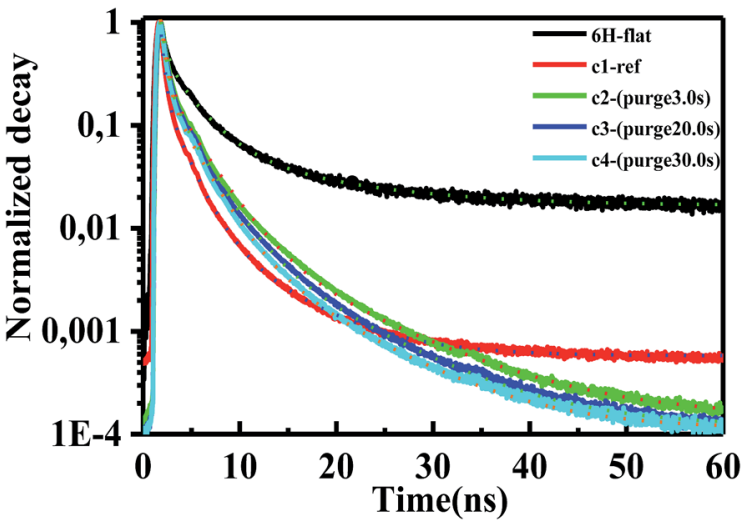

Fig. 9 Time-resolved PL (normalized) of flat $6 \mathrm{H}-\mathrm{SiC}$, porous samples $c_{1}, c_{2}, c_{3}$ and $c_{4}$. The decay curves were fitted with triple-exponential components. excitation, a pulsed diode laser (pulse width $\sim 44 \mathrm{ps}, 0.74 \mathrm{~mW}$ ) working at $375 \mathrm{~nm}$, controlled by a programmable laser driver (LDH-D-C-375 with PDL 820, PicoQuant GmbH), was focused onto the samples through a microscope. A burst mode excitation sequence was used to achieve a good signal-to-noise ratio in the measurement. In the burst mode, a pulse pattern was generated using the PDL 820 laser driver, consisting of 1 laser pulse followed by a waiting period of $62.5 \mathrm{~ns}$, resulting in a total frequency of $16 \mathrm{MHz}$. The time-resolved PL results are presented in Fig. 9. The mechanisms of lifetime quenching are revealed by the lifetimes of the respective triple-exponential fitting, which includes non-radiative and radiative surface recombination and recombination in bulk SiC. The luminescence decay can be adequately described by triple-exponential fits, as shown in Table 1 and Fig. 9 with dotted lines. The average PL lifetime was calculated by using $\tau_{\text {ave }}=\frac{\sum A_{i} \tau_{i}^{2}}{\sum A_{i} \tau_{i}}$,

Table 1 Lifetime components in time-resolved PL decay fitted by triple exponential components

\begin{tabular}{lclllrr}
\hline Samples & $\tau_{3}(\mathrm{~ns})$ & $A_{3}$ & $\tau_{2}(\mathrm{~ns})$ & $A_{2}$ & $\tau_{1}(\mathrm{~ns})$ & $A_{1}$ \\
\hline $6 \mathrm{H}-$ Flat & 11.93 & 0.061 & 2.87621 & 0.7283 & 0.55017 & 12.9097 \\
$\mathrm{c}_{1}$ & 6.52159 & 0.0185 & 1.80673 & 0.52743 & 0.34148 & 135.8705 \\
$\mathrm{c}_{2}$ & 9.68234 & 0.01402 & 2.76457 & 0.48112 & 0.51831 & 28.18808 \\
$\mathrm{c}_{3}$ & 8.27814 & 0.01635 & 2.50885 & 0.50592 & 0.46771 & 0.3843 \\
$\mathrm{c}_{4}$ & 7.91918 & 0.01458 & 2.38284 & 0.49494 & 0.45355 & 0.7815 \\
& & & & & & 0.6514 \\
& & & & & & 0.6113
\end{tabular}


where $\tau_{i}$ and $A_{i}(i=1,2,3)$ represent the lifetime and weight factor of each component. ${ }^{26}$ The average lifetime in bulk $6 \mathrm{H}$-SiC and porous samples $\mathrm{c}_{1}, \mathrm{c}_{2}, \mathrm{c}_{3}$ and $\mathrm{c}_{4}$ is $1.89 \mathrm{~ns}, 0.38 \mathrm{~ns}, 0.78 \mathrm{~ns}$, $0.65 \mathrm{~ns}$ and $0.61 \mathrm{~ns}$, respectively. Surface defects related nonradiative recombination quenches the PL lifetime in the porous samples. As expected the lifetime is susceptible to surface passivation, so the average lifetime in sample $c_{2}$ increased after passivation. It appears that the increase of ALD purge time results in a decrease of such radiative recombination channels. For longer purge times, the top layer of the porous sample might be oxidized in the ALD chamber thereby decreasing the passivation effect.

\section{Conclusions}

Porous B-N co-doped SiC samples were prepared by anodic oxidation of $6 \mathrm{H}-\mathrm{SiC}$ substrate. The PL emission peak is blue shifted to around $520 \mathrm{~nm}$ due to surface defects and quantum confinement effect of B-N donor-acceptor-recombination in porous $6 \mathrm{H}-\mathrm{SiC}$. The XRD patterns shows shoulder peaks of reflection from surface inclusions on the porous samples. Significant enhancement of the PL intensity was observed from porous SiC after deposition and annealing of $\mathrm{ALD} \mathrm{Al}_{2} \mathrm{O}_{3}$ films. The thickness, annealing time, annealing temperature, and precursor purge time were optimized in term of strong PL. In order to study the passivation mechanism and penetration depth, XPS measurements were performed to check the chemical bonds in passivated porous SiC. It has been confirmed that the passivation effect is attributed to the $\mathrm{OH}$ bonds in $\mathrm{Al}_{2} \mathrm{O}_{3}$ films, which suppressed the non-radiative recombination after annealing. Moreover, the average carrier lifetime in $\mathrm{Al}_{2} \mathrm{O}_{3}$ passivated samples is longer than original porous SiC. However, there is a trade-off between the passivation and the oxidation effect during ALD deposition and annealing process. As a consequence, we draw the conclusions that the optimized passivation condition for porous $\mathrm{SiC}$ is $20 \mathrm{~nm}$ thickness of $\mathrm{Al}_{2} \mathrm{O}_{3}$, deposited at $160{ }^{\circ} \mathrm{C}$ and with a purge time of $20 \mathrm{~s}$, followed by an annealing for $5 \mathrm{~min}$ at $350{ }^{\circ} \mathrm{C}$. In addition, the redshift phenomenon indicates that emission in porous $\mathrm{SiC}$ is mainly attributed surface defects. Such fundamental investigation provides valuable information to understand the emission mechanism and improve the emission efficiency in porous SiC based optical applications.

\section{Acknowledgements}

This work was supported by Innovation Fund Denmark (project No. 4106-00018B).

\section{Notes and references}

1 S. Kamiyama, et al., Fluorescent SiC and its application to white light-emitting diodes, J. Semicond., 2011, 32(1), 013004.

$2 \mathrm{H}$. Ou, et al., Advances in wide bandgap $\mathrm{SiC}$ for optoelectronics, Eur. Phys. J. B, 2014, 87(3), 58.
3 T. Nishimura, et al., High efficiency violet to blue light emission in porous SiC produced by anodic method, Phys. Status Solidi C, 2010, 7(10), 2459-2462.

4 T. Matsumoto, et al., Blue-green luminescence from porous silicon carbide, Appl. Phys. Lett., 1994, 64(2), 226-228.

5 T. L. Rittenhouse, Surface-state origin for the blueshifted emission in anodically etched porous silicon carbide, J. Appl. Phys., 2004, 95(2), 490.

6 Y. Shishkin, et al., Fabrication and morphology of porous p-type SiC, J. Appl. Phys., 2005, 97(4), 044908.

7 A. T. Cao, Q. N. T. Luong and C. T. Dao, Influence of the anodic etching current density on the morphology of the porous SiC layer, AIP Adv., 2014, 4(3), 037105.

$8 \mathrm{M}$. Leitgeb, et al., A Combination of Metal Assisted Photochemical and Photoelectrochemical Etching for Tailored Porosification of $4 \mathrm{H}$ SiC Substrates, ECS J. Solid State Sci. Technol., 2016, 5(10), P556-P564.

9 B. Hoex, et al., On the c-Si surface passivation mechanism by the negative-charge-dielectric $\mathrm{Al}_{2} \mathrm{O}_{3}$, J. Appl. Phys., 2008, 104(11), 113703.

$10 \mathrm{~W}$. W. Hsu, et al., Surface passivation of $\mathrm{Cu}(\mathrm{In}, \mathrm{Ga}) \mathrm{Se}_{2}$ using atomic layer deposited $\mathrm{Al}_{2} \mathrm{O}_{3}$, Appl. Phys. Lett., 2012, 100(2), 023508.

11 B. Dou, et al., Surface passivation of nano-textured silicon solar cells by atomic layer deposited $\mathrm{Al}_{2} \mathrm{O}_{3}$ films, J. Appl. Phys., 2013, 114(17), 174301.

12 N. Batra, et al., Influence of deposition temperature of thermal ALD deposited $\mathrm{Al}_{2} \mathrm{O}_{3}$ films on silicon surface passivation, AIP Adv., 2015, 5(6), 067113.

13 G. Agostinelli, et al., Very low surface recombination velocities on p-type silicon wafers passivated with a dielectric with fixed negative charge, Sol. Energy Mater. Sol. Cells, 2006, 90(18-19), 3438-3443.

14 G. Dingemans and W. M. M. Kessels, Status and prospects of $\mathrm{Al}_{2} \mathrm{O}_{3}$-based surface passivation schemes for silicon solar cells, J. Vac. Sci. Technol., A, 2012, 30(4), 040802.

15 A. Dillon, et al., Surface chemistry of $\mathrm{Al}_{2} \mathrm{O}_{3}$ deposition using $\mathrm{Al}\left(\mathrm{CH}_{3}\right)_{3}$ and $\mathrm{H}_{2} \mathrm{O}$ in a binary reaction sequence, Surf. Sci., 1995, 322(1), 230-242.

16 A. W. Ott, J. W. Klaus, J. M. Johnson and S. M. George, $\mathrm{Al}_{2} \mathrm{O}_{3}$ thin film growth on $\mathrm{Si}(100)$ using binary reaction sequence chemistry, Thin Solid Films, 1997, 292, 135-144.

17 L. Q. Zhu, et al., Atomic layer deposited $\mathrm{Al}_{2} \mathrm{O}_{3}$ films for antireflectance and surface passivation applications, Appl. Surf. Sci., 2014, 288, 430-434.

18 E. Sun, et al., Enhancement of photoluminescence intensity from $\mathrm{Si}$ nanodots using $\mathrm{Al}_{2} \mathrm{O}_{3}$ surface passivation layer grown by atomic layer deposition, Appl. Surf. Sci., 2010, 256(16), 5021-5024.

19 F. Kersten, et al., Role of Annealing Conditions on Surface Passivation Properties of $\mathrm{ALD} \mathrm{Al}_{2} \mathrm{O}_{3}$ Films, Energy Procedia, 2013, 38, 843-848.

20 M. B. González, et al., Charge trapping analysis of $\mathrm{Al}_{2} \mathrm{O}_{3}$ films deposited by atomic layer deposition using $\mathrm{H}_{2} \mathrm{O}$ or $\mathrm{O}_{3}$ as oxidant, J. Vac. Sci. Technol., B: Nanotechnol. Microelectron.: Mater., Process., Meas., Phenom., 2013, 31(1), 01A101. 
$21 \mathrm{M}$. Groner, et al., Low-temperature $\mathrm{Al}_{2} \mathrm{O}_{3}$ atomic layer deposition, Chem. Mater., 2004, 16(4), 639-645.

22 A. Richter, et al., Reaction kinetics during the thermal activation of the silicon surface passivation with atomic layer deposited $\mathrm{Al}_{2} \mathrm{O}_{3}$, Appl. Phys. Lett., 2014, 104(6), 061606.

23 G. Dingemans, et al., Influence of annealing and $\mathrm{Al}_{2} \mathrm{O}_{3}$ properties on the hydrogen-induced passivation of the $\mathrm{Si}$ / $\mathrm{SiO}_{2}$ interface, J. Appl. Phys., 2012, 111(9), 093713.
24 W. Lu, et al., Fabrication and surface passivation of porous $6 \mathrm{H}-\mathrm{SiC}$ by atomic layer deposited films, Opt. Mater. Express, 2016, 6(6), 1956.

25 J. S. Shor, et al., Direct observation of porous SiC formed by anodization in HF, Appl. Phys. Lett., 1993, 62(22), 2836-2838.

26 Y. A. Gromova, et al., Fluorescence energy transfer in quantum dot/azo dye complexes in polymer track membranes, Nanoscale Res. Lett., 2013, 8(1), 452. 